\title{
Evaluation of the Psychosocial Effects of Long-Term Genital HPV Infection
}

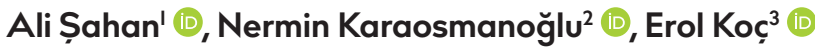 \\ 'Department of Dermatology, Doctor Al-Sa Aesthetic $\bar{\alpha}$ Cosmetic Dermatology Clinic, Ankara, Turkey \\ 2Department of Dermatology, Ankara Training and Research Hospital, Ankara, Turkey \\ ${ }^{3}$ Department of Dermatology, Medical Park Hospital, Ankara, Turkey
}

ORCID IDs of the authors: A.Ș. 0000-0003-082I-I7I0; N.K. 0000-0002-3462-I628; E.K. 0000-0003-4I47-2015.

Cite this article as: Șahan A, Karaosmanoğlu N, Koç E. Evaluation of the Psychosocial Effects of Long-Term Genital HPV Infection. Cyprus J Med Sci 2020; 5(I): 88-92.

\section{BACKGROUND/AIMS}

Genital human papillomavirus (HPV) infection is one of the most common sexually transmitted diseases. This study purposed to evaluate the psychosocial effects of long-term genital HPV infection.

\section{MATERIAL and METHODS}

Overall, 77 male patients with genital HPV infection were included. The Dermatological Life Quality Index (DLQI), State-Trait Anxiety Inventory scales (STAI I-2), and the Beck Depression Inventory (BDI) were used to assess the psychological burden of patients. In addition, they were evaluated by a psychiatrist.

RESULTS

The mean age was $37.68 \pm 11.67$. The mean duration of the disease was $9.74 \pm 7.76$ months. Overall, 51 patients $(66.2 \%)$ had more than five lesions. The mean score of the DLQI scale was noted to be $4.58 \pm 4.42$. Most patients (26; 33.8\%) were classified as "small effect on patient's life," at a score of 2-5. STAI-I mean score was 4I.74 11.77 . Thirty-eight patients (49.4\%) were noted to be highly anxious. According to the STAI-2 scale, the mean score was $42.69 \pm 9.71$, and most patients $(40 ; 51.9 \%)$ were noted to be highly anxious. The mean score of BDI was $16.43 \pm 11.929$, and 27 patients (35.1\%) were noted to be moderately depressive. The psychiatrist assessed 14 patients (I8.2\%) as needing psychiatric medication.

\section{CONCLUSION}

Generally, patients suffering from genital HPV for longer than 3 months are affected negatively psychosocially. Therefore, physicians should approach the patient with kindness, compassion, and patience. In addition, an expert psychiatrist's support should be sought if necessary.

Keywords: Dermatology life quality index, human papillomavirus, psychosocial effects

\section{INTRODUCTION}

Genital human papillomavirus (HPV) infection is a viral infection that is one of the most common sexually transmitted diseases in humans (I). HPVs are DNA viruses belonging to the Papillomaviridae family that can cause benign skin and mucosal lesions on the genital, anal, or oral mucosa, or may cause malignant lesions in various organs (2).

Patients with anogenital warts feel uncomfortable and are often ashamed of these lesions. They may resist consulting a physician, leading to delayed diagnosis. Furthermore, these patients may feel anxious or depressed $(3,4)$. Patients are consistently worried and anxious about developing anogenital cancers and its negative effects on their sex lives (5). Moreover, patients may have concerns regarding disease transmission and self-image, besides being embarrassed by the disease $(4,6)$.

This study evaluated the psychosocial effects of long-term genital HPV infection in men using the anxiety-depression tests, as well as a psychological evaluation by an expert psychiatrist.

Presented in: This study was presented at the " $4^{\text {th }}$ INDERCOS National Dermatology and Cosmetology Congress with International Participants- 2019 INDERCOS ". "27 th March, 2019, OP-2. Istanbul, Turkey". 


\section{MATERIAL AND METHODS}

This study included 77 male patients with genital HPV infection, lasting longer than 3 months, admitted to the outpatient clinic between December 2013 and May 2014. Patients over 18 years of age were included. The local ethics committee approved the study (November 12, 2013, 50687469-|49|-2338-13/1648-2499). All participants were informed regarding the study, and written consent was obtained.

All participants were evaluated by a dermatologist and a psychiatrist. Sociodemographic information, including age; smoking, alcohol, and drug use history; marital status; the number of sexual partners; educational status; working status; and the duration of the disease were recorded. A detailed anamnesis was obtained, and a careful dermatological examination was performed. Anamnesis included a history of genital warts, the existence of any extragenital warts, any co-existing sexually transmitted disease, or any medical treatments. Three validated questionnaires, namely the Dermatological Life Quality In$\operatorname{dex}(D L Q I)$, State-Trait Anxiety Inventory scales (STAI I-2), and Beck Depression Inventory (BDI), were used to assess patients' psychological burden. Patients were individually evaluated by an expert psychiatrist and were assessed using the Structured Clinical Interview for DSM-III-R (SCID I-2).

The Dermatological Life Quality Index (DLQI) is the first dermatology-specific quality-of-life instrument developed in 1994. It is a simple 10-question validated questionnaire. These 10 questions examine a patient's perception of the impact of skin diseases on different aspects of their health-related quality of life over the preceding week. The test is validated for adult dermatology patients aged 16 years and above.

Each question is scored on a 4-point Likert scale as follows: not at all or not relevant=0; a little=l; a lot=2; and very much=3. Scores of individual items (0-3) are added to yield a total score (0-30), wherein higher scores represent a greater impairment in patient's quality of life (7).

The Beck Depression Inventory (BDI) is an inventory including 21 items designed to assess the symptoms of depression as spec-

\section{Main Points:}

- Genital human papillomavirus (HPV) infection is one of the most common sexually transmitted diseases in humans.

- Patients with anogenital warts may feel uncomfortable, anxious or depressed. This study evaluated the psychosocial effects of long-term genital HPV infection in men using the anxiety-depression tests, as well as a psychological evaluation by an expert psychiatrist.

- $\quad$ Based on our results, HPV infections may affect a patient's quality of life, cause anxiety and depression, and may even cause psychosocial stress, thereby necessitating treatment.

- These patients should be approached with kindness, compassion, and patience to achieve treatment success. In addition, an expert psychiatrist's support can be pursued if necessary. ified in the Diagnostic and Statistical Manual of Mental Disorders-Fourth Edition. The 21 items are scored on a 4-point Likert scale ranging from 0 (absent) to 3 (severe). The total score ranges from 0 to 63. The Turkish version of this test was developed by Hisli (8).

The State-Trait Anxiety Inventory (STAI) is a commonly used measure of trait and state anxiety. It can be used in clinical settings to diagnose anxiety and distinguish it from depressive syndromes. Moreover, it is commonly used in research as an indicator of caregiver distress. All items are rated on a 4-point scale from "almost never" to "almost always." It contains 40 items, and for each subtest, scores range from 20 to 80 , with a higher score representing significant anxiety (9).

This test is a semi-structured interview to assess major axis I DSM-III-R diagnoses and is administered by a mental health professional. It is used to ensure that the major DSM-5 diagnoses are systematically evaluated. In addition, it can be used to characterize a study population in terms of current and previous psychiatric diagnoses (I0).

\section{Statistical Analysis}

Statistical analyses were performed using the statistical software package Statistical Package for the Social Sciences for Windows I5.0 (SPSS Inc., Chicago, IL, USA). The normal distribution of data was assessed using the Kolmogorov-Smirnov test. Continuous and normally distributed variables were presented as means \pm standard deviations, and intra-group differences were investigated using the student's t-test. Continuous variables with non-normal distribution were expressed as medians (minimum-maximum), and differences between variables were analyzed using the Mann-Whitney U test. Categorical variables were expressed in percentages.

\section{RESULTS}

All the 77 patients were men with a mean age of $37.68 \pm 11.67$ years. Overall, 54 patients (70.1\%) had a history of smoking. Only 2 patients $(2.6 \%)$ had a history of drug abuse, whereas 33 patients (42.9\%) had a history of alcohol use, and 33 patients (42.9\%) described a history of extramarital sexual intercourse. Overall, 30 patients (39\%) were single, whereas 47 (61\%) were married. In addition, 76 patients (98.7\%) graduated from at least high school, and $58(75.3 \%)$ had a job, whereas $19(24.7 \%)$ did not work. Eight patients ( $10.4 \%$ ) had a history of genital warts. Extragenital warts were observed in 21 (27.3\%) patients. None of the patients had any other sexually transmitted diseases. The mean duration of the disease was $9.74 \pm 7.76$ months. Overall, 51 patients $(66.2 \%)$ had more than five lesions, and 68 patients ( $88.3 \%$ ) had a history of taking medications for the disease. Nine patients (II.7\%) had no history of treatment.

Upon review, no previous studies had explored the extent of lesion prevalence and the length of lesion duration. Therefore, we defined the term 'diffuse lesion' as those having more than five lesions and the term 'long-term lesion' as those having disease longer than 3 months.

The mean score of the DLQI scale was $4.58 \pm 4.42$. The scores of the scale are presented in Table I. Most patients were classified as a "small effect on patient's life" at a score of 2-5 (26 patients, 
33.8\%). The STAI-I mean score was 4I.74 \pm 1.77 , and overall, $38 \mathrm{pa-}$ tients $(49.4 \%)$ were highly anxious. The STAI- 2 mean score was $42.69 \pm 9.71$, with most patients (40; $51.9 \%$ ) being highly anxious. Detailed STAI I-2 scores are illustrated in Table 2. The mean BDI

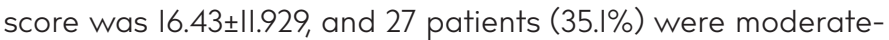
ly depressed, whereas most patients $(37 ; 48.1 \%$ ) had a normal mood. The BDI scores are presented in Table 3. Overall, $7.8 \%$ of patients had a history of psychiatric medication, and $9.1 \%$ were still taking psychiatric medication during the study. Finally, after evaluating all patients with the help of an expert psychiatrist and testing them by using the SCID I-2 tests, 63 patients (8I.8\%) were noted to have a normal mood and required no medication, whereas $14(18.2 \%)$ required psychiatric medication.

Patients with a history of genital warts were noted to have a higher rate of worsening mental health compared with patients

\begin{tabular}{|c|c|c|c|c|}
\hline DLQI & Frequency & Percentage & $\begin{array}{l}\text { Valid } \\
\text { Percentage }\end{array}$ & $\begin{array}{l}\text { Increasing } \\
\text { percentage }\end{array}$ \\
\hline Unaffected & 25 & 32.5 & 32.5 & 32.5 \\
\hline Little effect & 26 & 33.8 & 33.8 & 66.2 \\
\hline Moderate effect & 16 & 20.8 & 20.8 & 87.0 \\
\hline Very much affected & 10 & 13.0 & 13.0 & 100.0 \\
\hline Total & 77 & 100.0 & 100.0 & \\
\hline
\end{tabular}

TABLE 2. STAI I-2 scores of patients

\begin{tabular}{lcccc|} 
STAl-I & Frequency & Percentage & $\begin{array}{c}\text { Valid } \\
\text { Percentage }\end{array}$ & $\begin{array}{c}\text { Increasing } \\
\text { percentage }\end{array}$ \\
\hline No anxiety & 21 & 27.3 & 27.3 & 27.3 \\
Little anxious & 18 & 23.4 & 23.4 & 50.6 \\
Highly anxious & 38 & 49.4 & 49.4 & 100.0 \\
Total & 77 & 100.0 & 100.0 & \\
STAl-2 & & & & \\
No anxiety & 20 & 26.0 & 26.0 & 26.0 \\
Little anxious & 17 & 22.1 & 22.1 & 48.1 \\
Highly anxious & 40 & 51.9 & 51.9 & 100.0 \\
Total & 77 & 100.0 & 100.0 & \\
\hline STAl: State-Trait Anxiety Inventory & & & \\
\hline
\end{tabular}

TABLE 3. BDI scores of patients

\begin{tabular}{|lcccc|} 
STAl-I & Frequency & Percentage & $\begin{array}{c}\text { Valid } \\
\text { Percentage }\end{array}$ & $\begin{array}{c}\text { Increasing } \\
\text { percentage }\end{array}$ \\
\hline Normal & 37 & 48.1 & 48.1 & 48.1 \\
Little mental disorder & 7 & 9.1 & 9.1 & 57.1 \\
$\begin{array}{l}\text { Borderline clinical } \\
\text { depression }\end{array}$ & 1 & 1.3 & 1.3 & 58.4 \\
$\begin{array}{l}\text { Moderate depression } \\
\text { Severe depression }\end{array}$ & 27 & 35.1 & 35.1 & 93.5 \\
Total & 5 & 6.5 & 6.5 & 100.0 \\
\hline BDI: Beck Depression Inventory & & 100.0 & \\
\hline
\end{tabular}

who had no history of genital warts $(\mathrm{p}=0.001)$. On the other hand, patients with a history of extragenital warts had less worsening of their mental health than patients with no history of extragenital warts $(p=0.006)$. The mental health of patients with more than five lesions was worse than that of patients with fewer than five lesions $(p=0.02)$. The mental health of patients with a history of any psychiatric medication use was worse than that of patients with no history of psychiatric mediation use $(p=0.005)$. Moreover, patients with a history of extragenital warts had a higher rate of having more than five lesions ( $p=0.027$ ).

Patients with more than five lesions had a longer duration of lesions $(p=0.00048)$. Patients with a history of psychiatric medication use had a higher rate of extensive lesions (more than five) compared with patients not taking psychiatric medication $(p=0.048)$. Patients with a history of extragenital warts had a longer duration of lesions compared with patients with no history of extragenital warts $(p=0.06)$.

We observed that DLQI scores decreased with the increase in the duration of time with lesions $(p=0.005)$. Patients with multiple sexual partners had higher BDI scores than those having one sexual partner $(p=0.032)$. Patients with a history of extragenital warts had higher STAI-2 scores than those having no history of extragenital warts $(p=0.015)$. The increase in STAI-I and DLQI scores were similar $(p=0.043)$.

\section{DISCUSSION}

Genital Human Papillomavirus (HPV) -one of the most common sexually transmitted infections globally-might negatively affect patients psychosocially (II). The disease may cause feelings of depression, anger, or shame, as well as a loss of sexual desire or transformation of sexuality into an unpleasant experience (II, I2).

Based on our results, HPV infections may affect a patient's quality of life, cause anxiety and depression, and may even cause psychosocial stress, thereby necessitating treatment. Previous reports have revealed that the disease may cause a decrease in the quality of life and lead to psychosocial or sexual problems $(I, 4, I I-22)$. Even though the results of these studies are partially consistent with the present study, comparing these results is difficult because of the use of different evaluation tools. To the best of our knowledge, this is the first study evaluating the dermatological quality-of-life index, patient anxiety, and depression status with internationally validated tests, as well as consulting a psychiatrist to assess the patient's mental state. Therefore, our results are of merit to clinicians and can be used to improve patient care.

No significant relationship was observed between the extensiveness and duration of the lesions and a history of smoking, drug abuse, or alcohol abuse. The test scores were not affected by a history of smoking, drug, or alcohol abuse. However, no control group was available for comparison of these results.

Worsening mental health in patients with a history of genital warts could be due to the infection becoming more resistant to treatment modalities over time and limited patient understanding of the disease severity over time. Hence, the experience of each patient varies. 
We noted that a history of extragenital warts protected against a decrease in mental health compared with patients with no history of extragenital warts. Probably these patients become accustomed to having extragenital warts and are not distressed when the same lesions occur in the genital region; thus, their mental health is not affected.

Our results indicated that having more than five lesions may affect mental health compared with having fewer lesions. This finding suggests that more extensive lesions may cause more anxiety, concern, and psychological stress in patients. Patients with a history of psychiatric medication use were more inclined to mental distress. This possibility could be because these patients are not as well equipped to deal with new problems as their healthy counterparts.

Patients with a history of extragenital warts were prone to having more than five lesions in the genital region. This finding could be explained by the autoinoculation of warts. Moreover, because the immune system does not tolerate this condition, more extensive lesions may occur in the genital region.

Patients with more than five lesions were observed to have a longer lesion duration. Notably, lesion prevalence increases with more resistant disease. Moreover, an increase in lesion duration increases the disease resistance.

Notably, patients with a history of psychiatric medication use had more extensive lesions than other patients. This result could be interpreted as patients with susceptibility to depression having more disease-related distress, with the intensive distress causing the disease to spread rapidly.

Furthermore, a history of extragenital warts increases lesion duration. In addition, an immune system prone to HPV infection may have difficulties clearing the infection. We showed that DLQI scores decreased as the duration of the lesions increased. This can be interpreted as the patient adjusting to the disease over time or that the patient lacks information on the disease.

Patients with a history of multiple sexual partners had higher BDI scores. This result suggests that depression can lead the patient to polygamy as an escape mechanism. In addition, it can be concluded that having multiple sexual partners can cause distress, leading to patient depression.

A history of extragenital warts results in increased STAI-2 scores. This result suggests that when the patient is familiar with the disease, the concern and anxiety of the individual increases.

Notably, only one previous study had used DLQI to evaluate the effects of genital and extragenital warts on the quality of life of patients (19). The authors observed that the overall DLQI scores of patients with extragenital warts were higher than those of patients with genital warts, and extragenital warts can negatively affect a patient's life. Nevertheless, the scores of patients in this study were lower than those in the present study, and generally, the disease was noted to have a small effect on the patient's quality of life.
Nonetheless, the fact that 14 patients (18.2\%) in the present study required psychiatric medication is a significant observation. However, further studies with large patient groups, including both men and women, as well as control groups, should be conducted to confirm our study results.

Conclusively, patients suffering from genital HPV for longer than 3 months are negatively affected psychosocially. Therefore, these patients should be approached with kindness, compassion, and patience to achieve treatment success. In addition, an expert psychiatrist's support can be pursued if necessary.

Ethics Committee Approval: Ethics committee approval was received for this study from the ethics committee of Gülhane Military Medical Academy. (50687469-149I-2338-13/1648-2499 - 12.11.2013).

Informed Consent: Written informed consent was obtained from patients who participated in this study.

Peer-review: Externally peer-reviewed.

Author contributions: Concept- A.Ș., E.K.; Design- A.Ș., E.K.; Supervision-N.K., A.Ș., E.K.; Resource:A.Ș., E.K.; Materials-A.Ș., E.K.; Data Collection and/or Processing- A.S., E.K.; Analysis and/or Interpretation-A.S.. E.K., N.K.; Literature Search- N.K., A.Ș.; Writing-N.K., A.Ș; Critical ReviewsN.K., A.S., E.K.

Conflict of Interest: The authors have no conflict of interest to declare.

Financial Disclosure: The authors declared that this study has received no financial support.

\section{REFERENCES}

I. Capra G, Giovanelli L, Bellavia C, Migliore MC, Caleca MP, Perino A et al. HPV genotype prevalence in cytologically abnormal cervical samples from women living in South Italy. Virus Res 2008; 133(2): 195-200. [CrossRef]

2. Paavonen J. Human papilloma virus infection and the development of cervical cancer and related genital neoplasias. Int J Infect Dis 2007; II(2 suppl): S3-9. [CrossRef]

3. Dediol I, Buljan M, Vurnek-A, Ivkovia M, Bulat $\bigvee$, A Itum M et al. Psychological burden of anogenital warts. J Eur Acad Dermatol Venereol 2009; 23(9): 1035-38. [CrossRef]

4. Van der Snoek EM, Couwenberg SM, Lammers AM, Van Loon AM. Anogenital warts: influence on quality of life in Dutch soldiers. Sex Transm Dis 2013; 40(8): 650-I. [CrossRef]

5. Mortensen GL. Long-term quality of life effects of genital warts-A follow up study. Dan Med Bull 2010; 57(4): A4I40.

6. Van der Snoeck EM, van Loon AM, Lammers AM, Couwenberg SM. Anogenital warts and human papilloma virus: knowledge, perceived nuisance and risk perception in Dutch soldiers. Int J STD AIDS 20I2; 23(7) :5I2-5. [CrossRef]

7. Finlay $A Y$, Khan GK. Dermatology life quality index (DLQI)-a simple practical measure for routine clinical use. Clin Exp Dermatol 1994; 19(3): 210-6. [CrossRef]

8. Hisli N. Reliability and validity of Beck Depression Inventory among university students. J Psychol 1989; 7(23): 3-13.

9. Marteau TM, Bekker H. The development of a six-item short-form of the state scale of the Spielberger State-Trait Anxiety Inventory (STAI). Br J Clin Psychol 1992; 3I(P+ 3): 301-6. [CrossRef]

10. Malihe Farahani, Seyyed Salman Alavi, Mahmood Mirzamani Bafghi, Sudeh Esmaili Alamuti, Zohreh Taghavi, Mohammadreza Mohammadi. Psychological factors including demographic features, mental illnesses, and personality disorders as predictors in internet addiction disorder. Iran J Psychiatry 2018; I3(2): 103-I0. 
II. Clarke P, Ebel C, Catotti DN, Stewart S. The psychosocial impact of human papilloma virus infection: implications for healthcare providers. Int J STD and AIDS 1996; 7(3): 197-200. [CrossRef]

12. Filiberti A, Tamburini M, Stefanon B, Merola M, Bandieramonte G, Ventafridda $V$ et al. Psychosocial aspects of genital human papilloma virus infection: a preliminary report. J Psychosom Obstet Gynaecol 1993; 14(2); 145-52. [CrossRef]

13. Graziottin A, Serafini A. HPV infection in women: psychosexual impact of genital warts and intraepithelial lesions. J Sex Med 2009; 6(3): 633-45. [CrossRef]

14. Garrido-Rios AA, Sanz-Munoz C, Miranda-Sivelo A, Miranda-Romero A. Major depressive episode secondary to condylomata acuminata. GenHosp Psychiatry 2010 32(4): 446.e3-446.e3-5. [CrossRef]

15. Ireland JA, Reid M, Powell R, Petrie KJ. The role of illness perceptions: psychological distress and treatment-seeking delay in patients with genital warts. Int J STD AIDS 2005; 16(I0): 667-70. [CrossRef]

16. Drolet M, Brisson M, Maunsell E, Franco EL, Coutlee F, Ferenczy A et al. The impact of anogenital warts on health-related quality of life: a six-month prospective study. STD 20II; 38(10): 949-56. [CrossRef]

17. Senecal M, Brisson M, Maunsell E, Ferenczy A, Franco EL, Ratnam $\mathrm{S}$ et al. Loss of quality of life associated with genital warts: base- line analyses from a prospective study. Sex Transm Infect 20II; 87(3): 209-15. [CrossRef]

18. Shi J, Kang DJ, Qi SZ, Wu H, Liu Y, Sun L et al. Impact of genital warts on health related quality of life in men and women in mainland China: a multicenter hospital-based cross-sectional study. BMC Public Health 2012; 12: 153. [CrossRef]

19. Salah E. Impact of multiple extragenital warts on quality of life in immune-competent Egyptian adults: a comparative cross-sectional study. Clin Cosmet and Investig Dermatol 2018:II 289-295. [CrossRef]

20. Paradisi A, Capizzi R, Ricci F, Di Pietro C, Abeni D, Tabolli S. Quality of life in patients with anogenital warts. Eur J Dermatol 2013; 23(6): 837-42. [CrossRef]

21. Ferenidou F, Salakos N, Vaidakis N, Paltoglou G, Bakalianou K, Papadimitriou $\mathrm{G}$ et al. The impact of HPV diagnosis on women's sexual and mental health: preliminary findings. Clin Exp Obstet Gynecol 2012; 39(I): 79-82.

22. Nahidi M, Nahidi Y, Saghebi A, Kardan G, Jarahi L, Aminzadeh B ef al. Evaluation of Psychopathology and Quality of Life in Patients with Anogenital Wart Compared to Control Group. Iran J Med Sci 2018; 43(I): 65-9. 